\title{
Particle size distribution analysis for the rapid detection of microbial infection of urine
}

\author{
C. S. DOW 1 , A. D. FRANCE 1 , M. S. KHAN 2 , AND T. JOHNSON 2 \\ From the ${ }^{1}$ Department of Biological Sciences, University of Warwick, Coventry CV4 $7 A L$ and the \\ ${ }^{2}$ Department of Medical Microbiology, Group Pathology Laboratory, Warwick Hospital, Warwick, UK
}

SUMMARY The accuracy and practicality of particle size distribution analysis for rapid screening of urine specimens are assessed. Six hundred urines were subjected simultaneously to routine bacteriological examinations and particle size distribution analysis using a Coulter Counter (ZBI) linked to a C1000 Channelyzer. There was complete agreement in the results of $593(98.8 \%)$ specimens. Characteristic profiles of various bacterial species in infected specimens were consistently obtained. This system can easily be linked to any existing computer reporting in a district hospital laboratory, and the results of negative specimens $(70-80 \%)$ can be obtained within 5-10 minutes.

Urine specimens usually constitute a major part of a routine microbiological laboratory's workload. About two-thirds of these specimens are microscopically and bacteriologically negative.

Since the introduction of the colony count for the determination of significant bacteriuria (Kass, 1956) many other methods have been introduced, including the use of calibrated loops (Hoeprich, 1960) and dipslides (Mackey and Sandys 1965). More recently, rapid and automated methods have been tried, for example, the detection of bacterial adenosine 5'-triphosphate (Alexander et al., 1976; Johnston et al., 1976), changes in electrical impedance (Specter et al., 1976), microcalorimetry (Bettelheim et al., 1976), and radiometry (Bachrach, 1976). The Fn Coulter Counter has also been evaluated for the routine diagnosis of bacteriuria (Smither, 1977). None of these procedures has, however, gained general acceptance.

We have developed and assessed particle distribution analysis (ZBI Coulter Counter linked to a C1000 Coulter Channelyzer) for the rapid screening of urine specimens.

\section{Material and methods}

Six hundred urine specimens from male and female patients received at the pathology laboratory at Warwick General Hospital were each divided into two parts-one for routine microscopic and bacteriological examination, the other for analysis by

Received for publication 31 July 1978 particle size distribution. The samples were kept at $4^{\circ} \mathrm{C}$ and examined within one hour of receipt. The results of particle size distribution analysis and bacteriological cultures were compared only when all 600 specimens had been examined.

\section{MICROSCOPY AND CULTURE METHODS}

Cell counts were performed on well-mixed specimens using an improved Neubaeur counting chamber. A centrifuged deposit was examined for casts, crystals, debris, or any other constituents. Using a dip-strip, the $\mathrm{pH}$, presence or absence of reducing substances, and protein were also recorded.

Cultures were performed using a standard loop technique together with a blotting paper strip method (Leigh and Williams, 1964). The specimens were seeded onto cystine-lactose-electrolyte deficient (CLED) agar (Diamed Diagnostic) and incubated at $37^{\circ} \mathrm{C}$ overnight. A drop of urine was also placed on the surface of a Diagnostic Sensitivity Test (DST) agar plate which had been pre-inoculated with Escherichia coli NCTC 10418 and incubated in a similar manner. This was for the detection of antibacterial substances. Plates were examined after 18-24 hours' incubation. A bacterial count of $10^{5}$ organisms per $\mathrm{ml}$ or more in pure culture, or occasionally of two species of organisms, was considered to be significant. Taking into consideration the microscopic picture, the presence or absence of antimicrobial substances, and the clinical history, the results were divided into:
(a) significant bacteriuria (positive)
(b) doubtful significance (requiring repeat specimen) 
(c) contaminants

(d) no growth.

Specimens showing no growth in the presence of pus cells were investigated for renal tuberculosis as well as for auxotrophs and anaerobic organisms.

\section{PARTICLE SIZE DISTRIBUTION ANALYSIS}

\section{Instrumentation}

The Coulter Counter (ZBI) when linked to a C1000 Channelyzer (particle distribution analyser) permits rapid, accurate, and reproducible cell volume distribution analysis of microbial populations. The above system will resolve particles having a spherical diameter from $0.4 \mu \mathrm{m}\left(0.034 \mu \mathrm{m}^{3}\right)$ upwards (Dow, 1976) (Fig. 1).

The basic principle on which the instrumentation operates is comparatively simple (Fig. 2). The amplitude of the voltage pulse produced by nonconducting particles passing through the orifice is proportional to the volume of the particle, the relationship being linear. It is this signal which is amplified and analysed by the particle distribution analyser, producing an $\mathrm{XY}$ plot of cell volume versus relative cell number.

Variations in line voltage to both instruments were suppressed using a Belling Lee radio frequency interference filter. In addition, to alleviate 'atmospheric' interference, a screened electrode was used routinely. The instrumentation was not physically isolated nor were special precautions enforced during operation other than good laboratory procedures.

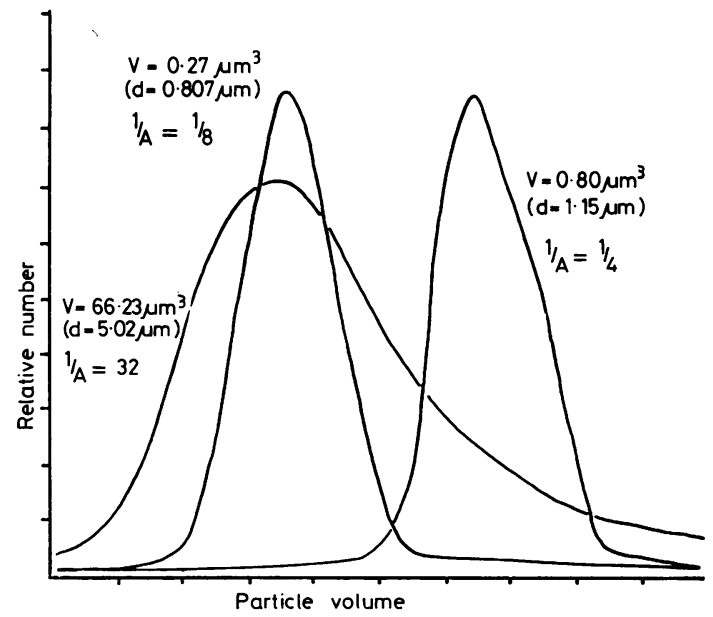

Fig. 1 Particle size distribution analysis of calibration latex particles: $V=$ particle volume, $d=$ particle diameter, $A=$ amplification, 1/aperture current $=$ $0 \cdot 354$ in all instances.

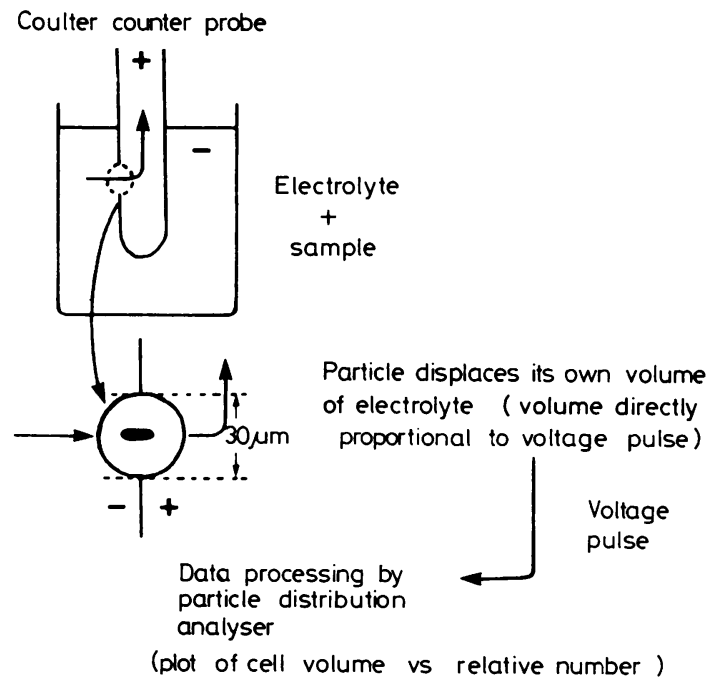

Fig. 2 Diagrammatic summary of particle size distribution analysis by an electronic counter.

By experimentation the instrument settings were optimised and were as follows:

A $30 \mu \mathrm{m}$ orifice was used exclusively, the aperture current was maintained at an instrument setting of $0 \cdot 354$, the amplification being varied between 8 and $1 / 32$ (instrument setting of $\frac{1}{8}$ and 32). The particle distribution analyser base channel threshold and window width were 15 and 100 respectively. The matching switch was kept at $40 \mathrm{~K}$.

\section{Specimen preparation}

In all tests the electrolyte used was pre-filtered Isoton (Coulter Electronics Ltd). Filtration was through a $0.22 \mu \mathrm{m}$ Millipore or Gelman Hawksley disposable unit (Lancing, Sussex).

A range of sample dilutions were examined. Of these, a 1/40 dilution was optimal for the detection of microbial species. There was no significant crystal or debris interference at this dilution other than viscous samples, which contained mucilagenous material or mucoprotein in high concentrations. The latter were the only specimens the instrumentation could not assay. Dilutions of greater than $1 / 70$ failed to detect a low bacterial count, while a dilution of 1/20 did not render the assay more sensitive but did increase the incidence of particulate interference. However, significantly less interference or orifice blockage, even at the latter dilution, from crystals, crystalloids, epithelial, red, and white cells, or mucoprotein was experiencer than might have been expected and in no way constituted a major problem. The reduction in particulate interference is in part explained by the dilution of sample into electrolyte 
and to the use of an edit circuit on the C1000. This refinement identifies asymmetric (abnormal) voltage pulses and rejects them. Consequently, the volume distribution profile is more precise and bears little comparison with a straight particle count as obtained from the ZBI.

The appropriate sample volume was diluted in electrolyte in a disposable blood cell counting vial

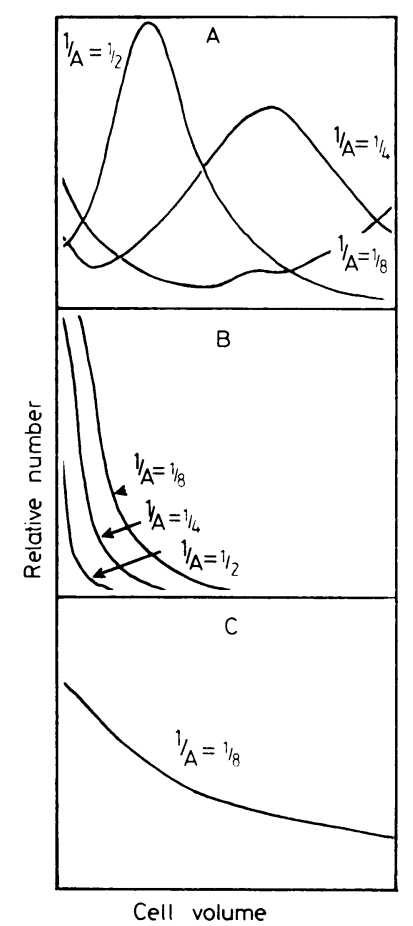

Fig. 3 (A) Particle size distribution analysis of an Escherichia coli culture at three amplification settings using constant current. (B) Particle size distribution analysis of a clinical urine specimen which bacteriologically proved to be negative. (C) Particle size distribution profile characteristic of crystal interference.
(Coulter Electronics Ltd) and examined immediately.

ANALYSIS AND INTERPRETATION OF RESULTS After dilution into electrolyte, specimens were subjected to particle distribution analysis by the following procedure. With a count range of $4 \mathrm{~K}$, each sample was analysed for one minute at each of the following amplifications: 2,4 , and 8 for bacterial cells (instrument settings of $\frac{1}{2}, \frac{1}{4}$, and $\frac{1}{8}$ ) and $1 / 16$ and 1/32 for red and white cells (instrument settings of 16 and 32). The data obtained from the lower amplifications were recorded as XY plots; the red and white cells were recorded simply as present or absent. The time factor involved in such an investigation from receipt of the sample to classification was approximately 5 minutes.

The results were recorded according to the following criteria:

(a) Positive: Samples that raised the base line, particularly the right-hand side of the graphs, with high amplification.

(b) Negative: Samples that produced no base line response.

(c) Questionable: Samples that raised the base line but gave uncharacteristic profiles. These were routinely scored as positive, as were samples that were unsuitable for analysis, for example, those with a high mucilagenous or mucroprotein content.

Theoretically, with this apparatus no falsenegatives (bacteriologically positive, particle distribution analysis negative) should be obtained. To alleviate any such possibility, particularly with early infections (less than $10^{5}$ organisms per $\mathrm{ml}$ ), any specimen that showed raising of the base line was regarded as positive.

With respect to detection limits by the instrumentation described, when calibrated with known concentrations of exponentially growing $E$. coli, counts of $5 \times 10^{4} \mathrm{ml}^{-1}$ represented the lower confidence limit. Sensitivity is therefore of the required magnitude (Brumfitt et al., 1973).

Table 1 Comparative results of particle distribution analysis and bacteriological culture methods

\begin{tabular}{|c|c|c|c|}
\hline Particle distribution analysis & No. of specimens & Bacteriological analysis & No. of specimens \\
\hline Positive profile & 105 & $\begin{array}{l}\text { Significant bacteriuria after } 18-24 \mathrm{~h} \\
\text { incubation } \\
\text { Significant bacteriuria after further } \\
\text { incubation and repeat culture for } \\
\text { anaerobe } \\
\text { Doubtful significance reported and } \\
\text { repeat specimen requested }\end{array}$ & 99 \\
\hline Negative profile & 466 & $\begin{array}{l}\text { repeat specimen requested } \\
\text { No growth obtained after } 18-24 \mathrm{~h} \\
\text { incubation } \\
\text { (Significant bacteriuria) }\end{array}$ & $\begin{array}{r}2 \\
465 \\
1\end{array}$ \\
\hline $\begin{array}{l}\text { Mixed profile (considered as } \\
\text { doubtful) }\end{array}$ & 29 & No significant growth/contaminants & 29 \\
\hline
\end{tabular}




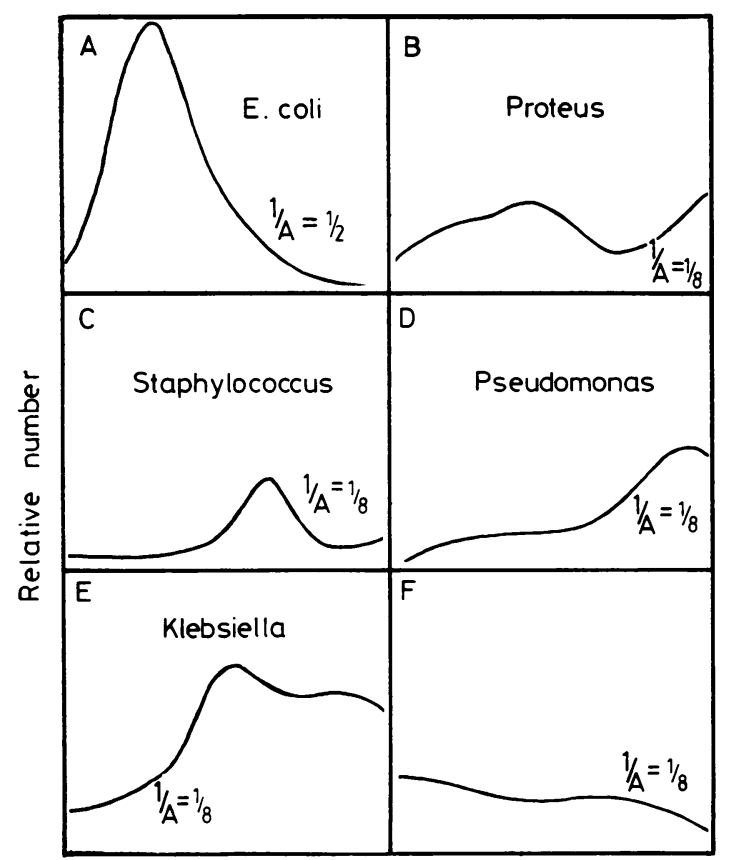

Cell volume

Fig. 4 Particle size distribution analysis characteristic of infected urines: $\mathrm{F}=$ Profile characteristic of a patient who formerly had infected urine and was treated with antibiotics.

\section{Results and discussion}

The characteristic particle distribution graphs of both positive and negative urine specimens are shown in Figure 3. The presence of microorganisms, for example, $E$. coli, in urine gave a profile similar to that shown in Fig. 3A, a non-infected urine (without crystals and ureates) gave a profile similar to that in Fig. 3B while crystal interference in a negative specimen gave a profile similar to that in Fig. 3C. The latter were designated as negative if there was no base line response at lower amplifications.
A comparison of the results obtained from routine laboratory methods and particle distribution analysis are shown in Table 1. Of 105 specimens recorded as positive by particle distribution analysis, 99 were positive bacteriologically. Of the six outstanding specimens, on repeat examination and culture on blood agar and chocolate agar plates under aerobic, $\mathrm{CO}_{2}$, and anaerobic conditions, three proved to be positive for anaerobic cocci and one specimen yielded a corynebacterium after 48 hours' incubation. The remaining two, although containing $10^{5}$ organisms per $\mathrm{ml}$, were thought to be of doubtful significance due to delay in transport and absence of pus cells as well as clinical evidence of infection. Repeat specimens were requested and no growth was obtained from them.

The most important feature of these data was that 466 specimens were recorded as being negative by particle distribution analysis while bacteriological culture gave a figure of $\mathbf{4 6 5}$ specimens showing no growth. There were no instances of a postive urine being recorded negative. The one case shown in Table 1 was later proved to be a transcription error since this patient was negative on repeat examination.

Non-characteristic profiles were recorded in 29 instances by particle distribution analysis. These were shown bacteriologically to be of less than $10^{5}$ organisms per $\mathrm{ml}$, or showed no significant growth, or were considered to be contaminants. It was found that in several instances patients with a confirmed diagnosis of urinary tract infection and who were being given antibiotic treatment gave unique and characteristic particle distribution profiles (Fig. 4F).

Each bacterial species, when in the exponential growth phase, presents characteristic and defined particle distribution profiles (Fig. 4). These graphic 'fingerprints' may be of value in making a preliminary identification of the infecting microbial species. The profiles shown in Fig. 4 were of individual specimens, the details of which are given in Table 2.

From the above results it is apparent that this procedure has considerable potential for the screening

Table 2 Details of samples: cell volume distribution profiles are given in Fig. 4

\begin{tabular}{|c|c|c|c|c|c|}
\hline Sample profile & Organisms isolated & $W B C / \mathrm{cm}^{2}$ & $\begin{array}{l}\text { Epithelial cells }+ \\
R B C \text { etc. }\end{array}$ & Crystals & $p H$ \\
\hline $\begin{array}{l}\text { A } \\
\text { B } \\
\text { C } \\
\mathbf{D} \\
\text { E } \\
\mathbf{F}\end{array}$ & $\begin{array}{l}\text { Escherichia coli } \\
\text { Proteus mirabilis } \\
\text { Staphylococcus albus } \\
\text { Pseudomonas } \\
\text { pyocyanea } \\
\text { Klebsiella species } \\
\text { No growth (patient } \\
\text { currently on antibiotic } \\
\text { for urinary tract } \\
\text { infection) }\end{array}$ & $\begin{array}{r}>500 \\
500 \\
>500 \\
\\
>500 \\
>500\end{array}$ & $\begin{array}{l}\text { Nil } \\
\text { Nil } \\
\text { Nil } \\
\text { Nil } \\
\text { Cellular debris }\end{array}$ & $\begin{array}{l}\text { Nil } \\
\text { Nil } \\
\text { Ureates } \\
\text { Nil } \\
\text { Nil }\end{array}$ & $\begin{array}{l}\text { Acid } \\
\text { Neutral } \\
\text { Acid } \\
\text { Acid } \\
\text { Acid }\end{array}$ \\
\hline
\end{tabular}


of urine specimens and the identification of significant bacteriuria. The stigma associated with electronic counters, that is, that of orifice blockage, was not a significant problem, rarely occurring even with urines containing high crystal concentrations. As previously mentioned, highly viscous urine samples could not be analysed and were consequently scored positive and subjected to routine bacteriological analysis. However, such specimens constitute only a very low percentage of the total workload. The saving in cost per specimen is considerable in both material and labour. However, the greatest advantage is that the test is performed within minutes of sample receipt and the diagnosis is made, not only of the presence or absence of microbial infection but also of red and white cell content, the latter being obtained simply by decreasing the amplification.

An important aspect of this technique is that the data (particle distribution profiles) can be fed directly from the Coulter $\mathrm{C} 1000$ Channelyzer to a computer programmed to make the diagnosis (positive or negative) and to assign preliminary classification, if appropriate.

\section{References}

Alexander, D. N., Ederer, G. M., and Matsen, J. M. (1976). Evaluation of an adenosine 5'-triphosphate assay as a screening method to detect significant bacteriuria. Journal of Clinical Microbiology, 3, 42-46.

Bachrach, U. (1976). Radiometric methods for the detection of bacteria in biological fluids and in water. 2nd International Symposium on Rapid Methods and Automation in Microbiology, Cambridge, edited by H. H. Johnston and S. W. B. Newsom, p. 3. Learned Information (Europe), Oxford.

Bettelheim, K. A., O'Farrell, S. M., Al-Salihi, S., Swah, E. J., and Beezer, A. E. (1976). Clinical investigation into the potential use of microcalorimetry for the diagnosis of bacteriuria. 2nd International Symposium on Rapid Methods and Automation in Microbiology, Cambridge, edited by H. H. Johnston and S. W. B. Newsom, pp. 8-9. Learned Information (Europe), Oxford.

Brumfitt, W., Percival, A., and Williams, J. D. (1973). Estimation of bacteria and white cells in the urine. Broadsheet 80, pp. 1-11. Association of Clinical Pathologists, London.

Dow, C. S. (1976). Cell volume analysis. 2nd International Symposium on Rapid Methods and Automation in Microbiology, Cambridge, edited by H. H. Johnston and S. W. B. Newsom, pp. 97-98. Learned Information (Europe), Oxford.

Hoeprich, P. D. (1960). Culture of the urine. Journal of Laboratory and Clinical Medicine, 56, 899-907.

Johnston, H. H., Mitchell, C. J., and Curtis, G. D. W. (1976). An automated test for the detection of significant bacteriuria. Lancet, 2, 400-402.

Kass, E. H. (1956). Asymptomatic infections of the urinary tract. Transactions of the Association of American Physicians, 69, 56-64.

Leigh, B. A., and Williams, J. D. (1964). Method for the detection of significant bacteriuria in large groups of patients. Journal of Clinical Pathology, 17, 498-503.

Mackey, J. P., and Sandys, G. H. (1965). Laboratory diagnosis of infections of the urinary tract in general practice by means of a dip-inoculum transport medium. British Medical Journal, 2, 1286-1288.

Smither, R. (1977). Rapid screening for significant bacteriuria using a Coulter Counter. Journal of Clinical Pathology, 30, 1158-1162.

Specter, S., Throm, R., and Friedman, H. (1976). Screening for bacteriuria in the clinical microbiology laboratory by electrical/impedance monitoring. 2nd International Symposium on Rapid Methods and Automation in Microbiology, Cambridge, edited by H. H. 'ohnston and S. W. B. Newsom, pp. 13-14. Learned Information (Europe), Oxford.

Requests for reprints to: Dr C. S. Dow, Department of Biological Sciences, University of Warwick, Coventry CV4 7AL, UK. 